\title{
Circuit Design of Parallel Power Operation Equipment for Peak Power Reduction
}

\author{
Jaesoo Yang $^{\dagger} \cdot$ Donghan $\mathrm{Kim}^{++} \cdot$ ManDo $\mathrm{Kim}^{+++}$
}

\begin{abstract}
Recent use of electricity during peak hours electricity supply-demand imbalance is inevitable that limit power use force. Therefore, in this paper, a circuit of parallel power operation equipment for peak power reduction which saves the power to electricity storage device during the non-peak power time and supply from the storage power during the expected power shortages time is designed Through this circuitry, the peak power of the commercial power supply with the parallel operation and connection of the commercial power supply and the power supply of the inverter from electricity storage that is a key feature of PRS(Peak power Reduction System) can be controlled. In addition, in order to increase the efficiency, a Transless Power Circuit DC-AC inverter is developed. Moreover, a variable impedance control is applied to the storage of electric power of an Uninterruptible Power Supply associated with a commercial power source.
\end{abstract}

\footnotetext{
Keywords : Power Peak, Parallel Power Operation Equipment, Peak Power Control, Power Storage Device, Parallel Power Operation Circuit
}

\section{상전원의 피크치 전력 감소를 위한 전력병합장치 회로설계}

\author{
양 재 수 $·$ 김 동 한 $^{++} \cdot$ 김 만 도 ${ }^{+++}$
}

\section{요 약}

최근 전력의 수요공급 불균형으로 전력사용 피크시간대의 전력사용 강제 제한이 불가피하다. 따라서, 본 논문에서는, 피크전력이 발생하지 않는 시간대의 전기를 저장하고 전력부족이 예상되는 피크전력 시간대에는 저장전력을 공급하는 병렬운전 기기의 회로를 설계하는데 있다. 이 회로설계를 통하여, PRS의 핵심기능인 상용전원과 인버터 발생전원의 병렬연결 운용으로, 상용전원의 피크치 전력을 조절할 수 있었다. 또한 효율을 높이기 위하여 Transless Power Circuit DC-AC 인버터를 개발하였다. 더 나아가, 가변임피던스 제어를 적용하여 무정전 전원장치의 저 장전력을 상용전원과 연계함으로써, 기존의 무정전 전원장치에서 구현을 못하고 있는 저장전력 사용시간을 획기적으로 늘릴 수 있는 기술구현 가능성을 입증하였다.

키워드 : 전력 피크, 전력병합 장치, 피크치 전력제어, 에너지 저장장치, 병렬운전

\section{1. 서 론}

본 논문에서 제시하고자 하는 PRS(Peak Power Reduction System)는 일종의 피크전력 감소기기는 피크전력이 발생하 지 않는 시간대의 전기를 저장하고 전력부족이 예상되는 피 크전력 시간대에 저장전력을 공급하는 기기로 PRS의 핵심 기능인 상용전원과 인버터 발생전원을 병렬연결하고 상용전 원과 저장전력 공급비율을 자동 조절하면서 저장전력 공급

† 정 회 원 : 단국대학교 교수

†† 준 회 원: 경기정보산업협회 사업이사/그린에너지융합위원장

휘 정 회 원: 수원과학대학교 전자과 겸임교수

Manuscript Received: April 7, 2014

First Revision : June 26, 2014

Accepted : August 2, 2014

* Corresponding Author: Jaesoo Yang(jsyang@dankook.ac.kr)
시간을 확대하는 기기이다.

UPS(Uninterruptible Power Supplies) 전력제어기는 기존 의 무정전 전원장치 및 태양광, 풍력, 조력 발전 시장의 인 버터 시장에서 우수한 제품 경쟁력으로 진입할 수 있다. 무 선 원격제어 기능으로 순간정전, 일시정전 등에 대응하여 안정적인 전력 공급을 보장하고 국가적인 전력공급 비상시 대처 할 수 있는 수단으로 활용하고 있다.

본 논문에서는 이러한 점을 착안하여, 공급자 측에서도 피크전력 발생시점을 인지하고 지역별, 시간대별 저장전력 을 사용하게 제어하는 기술로 활용하여, 궁극적으로 가정과 중소규모 건물 또는 지역별 에너지 사용의 효율성을 극대화 하기 위한 상용전원과 저장장치와 병합하여 운영하도록 설 계하여, 동작 여부와 그 성능을 측정하였다 $[1-3,6,7]$. 


\section{2. 현황 분석}

\section{1 전력 에너지 현황}

모든 전력거래량은 정부의 절전노력에도 불구하고 지속적 으로 상승하는 추세이며, 발전설비 증설은 원자력발전의 문 제와 기후온난화 협약 등에 따른 설비확충이 지연되고 있 다. 또한 기후변화에 따른 냉난방 전력사용증가도 피크전력 시간대 상승이 불가피할 것으로 예상되어 전력수급 불균형 이 장시간 지속될 것이다 $[4,5]$.

Table 1. Comparison of the advantages and disadvantages of PRS \& ESS \& UPS

\begin{tabular}{c|c|c|c}
\hline 구분 & PRS & ESS & UPS \\
\hline \multirow{2}{*}{ 사용용도 } & $\begin{array}{c}\text { 중·소형 전력 } \\
\text { 분권형에 적합 }\end{array}$ & $\begin{array}{c}\text { 대 전력 } \\
\text { 집권형에 적합 }\end{array}$ & 중·소형전력 \\
\hline 가격 & 중·저가 & 고가 & 중·저가 \\
\hline 전력예비율확보 & 좋음 & 좋음 & 보통 \\
\hline 유지보수 & 쉽다 & 어렵다 & 쉽다 \\
\hline$\$ / K W$ & 600 & 1,000 & 800 \\
$\$ / K W h$ & 2,400 & 4,000 & 3,200 \\
전력변환효율 & $95 \%$ & $96 \%$ & $80 \%$ \\
\hline \multirow{3}{*}{ 장점 } & 상용화 쉬움, & 상용화 쉬움 & \\
& 고출력, 친환경 & 고출력 & 상용화 쉬움 \\
& 높은 변환효율 & 높은 변환효율 & \\
\hline 단점 & 실증사례 없음 & - & 낮은 변환효율 \\
\hline
\end{tabular}

자료 : 삼성SDI, 토러스투자증권 리서치센터(ESS는 단주기용 $\mathrm{LIB}$ 기준)

용도별 전력사용 추체는 산업용 전력 $53.7 \%$, 일반용 $24.4 \%$, 주택용 $15.7 \%$ 순으로 나타나고 있는데, 2010년 이후 해마다 여름-겨울철이면 되풀이되는 전력난, 하지만 실시간으로 전력이 부족한 것이 아니고 피크수요 시간대만 대응한다면 전력난을 해소할 수 있다.

한국의 경우, 에너지 생산비중 그래프에서 2010년 에너지 생산 비중을 보면 원자력이 $78.1 \%$ 로 1 위, 신재생에너지가 $14.8 \%$ 로 2 위, 다음은 수력, 석탄, $\mathrm{LNG}$ 순으로 나타난다. 석 탄의 양이 많지 않은 현 시점에서 원자력 에너지의 생산비 중이 높은 것을 볼 수 있다. 매년 에너지소비량은 경제성장 률을 넘어서고 있으며, 특히 한국이 2005 2010년 동안 $30.6 \%$ 증가율을 나타내고 있다[8-10].

\subsection{PRS 및 ESS와 UPS 특성 비교}

과잉 생산된 전력을 저장해두었다가 전력부족이 우려될 때 방전하여 전력수급을 안정화하는 역할을 하는 장치로 대 부분 같은 목적으로 사용되는 제품이다. 하지만 $\mathrm{PRS}$ 는 상용 전원과 병렬연결 동작을 우선으로 하고, 저장전력의 방전시 간을 조절하는 기능적 특징을 가진다.

기존의 $\mathrm{ESS}$ 나 UPS와는 다르게 저장전력의 사용시간을 조절할 수 있어 동급용량 기준으로 소형화를 할 수 있는 특 징이 있다. 또한 용량 증설도 상용전원과 병렬 연결기술로
쉽게 할 수 있는 장점을 가진다. 대 전력을 사용하는 산업 용은 $\mathrm{ESS}$ 로 중·소 전력은 사용하는 일반용과 가정용은 $\mathrm{PRS}$ 로 적용 확대한다면 보다 안정적인 전력 수요관리를 할 수 있을 것으로 판단된다[전력통계정보시스템(EPSIS)]. Table 1 은 $\mathrm{PRS}$ 와 $\mathrm{ESS}$ 및 $\mathrm{UPS}$ 의 장단점 비교를 보여준다[7].

정부에서 많은 관심을 갖고 추진하는 신 요금제는, 일반 시간대에는 상대적으로 낮은 요금을 책정하고 피크시간대에 높은 요금을 책정해 전력 소비자로 하여금 피크시간대 전력 수요를 줄이도록 유도하는 제도로, 완전 실시간 요금제에 비해 피크시간대 전력수요 절감효과가 크며, 가격변동의 위 험으로부터 전력소비자를 일부 보호한다는 측면에서 실시간 요금제에 비해 도입의 효과성이 높을 것으로 예상된다. 이 와 병행하여 여유전력 시간대에 에너지를 저장하고 저장된 전력을 피크전력 시간대에 활용할 수 있는 기기를 개발하고 고압 수용가인 대규모 공장을 제외한 저압수용가인 가정, 공장, 사무실, 상가에 적극 활용한다면 피크전력 발생 시 해 결 할 수 있는 대안이 될 것이다.

\section{3. 피크치 전력 제어 설계와 구현}

\section{1 기술구현 목표}

상용전원과 저장전력 공급비율을 자동 조절하는 UPS 전 력제어기는 기존 UPS 전원장치 대비 아래와 같은 연구개발 목표로 실험을 하였다. 그리고, Fig. 1은 PRS의 동작원리의 구성도를 보여준다[7].

- 역률, 효율 개선

- 소형, 모듈방식, 원가절감

- 장치간 및 상용전원과 병렬연결

- 상용전원과 저장전력 공급비율을 자동조절하는 기능

- 표준 모듈 방식으로 $1 \varnothing$ 구성으로 설계

- 1 Ø은 최대 $30 \mathrm{~kW}, 3 \varnothing$ 은 최대 $300 \mathrm{~kW}$ 까지 용량증설

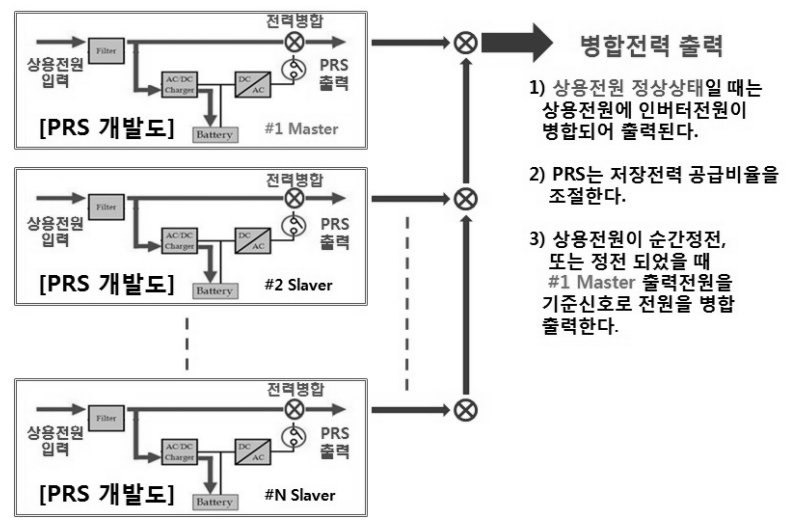

Fig. 1. The operation principle of the configuration of PRS

1) 상용전원 공급이 정상 상태일 때

개발된 PRS기기는 상용전원에 인버터전원이 병합되어 출 력되고, 저장전력의 공급비율 조절기능으로 효과적인 피크 전력감소제어를 할 수 있다. 


\section{2) 상용전원 공급이 이상 상태일 때}

상용전원에 이상이 발생되어 공급이 중단된 경우에는 \#1 Master 전원을 기준신호로 전력을 병합하고 저장전력을 $100 \%$ 공급하는 구조이다.

개발제품은 자체적으로 상용전원을 우선으로 동작하는 구 조로 인버터 발생전원은 상용전원과 병렬연결 되어 출력되 고 각 기기의 출력을 병렬 연결하는 구조이다. 각 기기의 상태를 제어하는 방식은 별도의 제어장치를 구성하지 않고 Master 장치에서 각 Slave 장치의 동작 상태를 인지하고 제 어하는 방식으로 구성한다. Master와 Slave 동작을 선택할 수 있고 본 과제를 통해 개발되는 병렬연결 수량은 하나의 Master 장치에 10 개의 Slave 장치를 연결하는 것으로 개발 하고, 상용화 후 하나의 Master 장치에 30개의 Slave 장치 를 연결할 수 있도록 개발한다.

상용전원과 병렬연결하면 전원계통의 단락용량이 증가하 게 된다. 이 단락용량이 일반 수용가 차단기의 차단용량을 초과하는 경우에는 수용가의 구내 사고 시에 차단불능이 될 수 있고, 인입 케이블의 순시 허용전류를 초과하는 경우에 는 이들의 손상을 초래할 우려가 있다. 따라서 본 기기 개 발의 핵심기술인 가변 임피던스회로 적용 및 과전압, 부족 전압, 단락방향, 주파수, 역전력, 부족전력 변동을 실시간으 로 검출하는 안전회로를 구성하여 병렬운전, 단독운전을 전 원 입력상태에 따라 제어한다.

\subsection{PRS 회로설계}

1) 전체 회로 구성도

Fig. 2의 정류부에서 $220 \mathrm{VAC}$ 입력을 풀 브릿지한 $\mathrm{DC}$ 전 압으로 인버터에서 $220 \mathrm{VAC}$ 출력을 발생시킬 수 없어서 통 상 출력 측에 $1: 1.5$ 또는 $1: 2$ 출력 트랜스를 사용 출력전압 을 발생시킨다. 출력 트랜스를 사용하면 소형, 모듈화 제작 이 불가능하므로 이를 해결하기 위해 첫 번째 방법은 $\mathrm{PFC}$ (Power Factor Correlation)회로를 채용 $\mathrm{DC}$ 전압을 승 압하여 적용하는 방법과 반파 배전압회로를 검토하였고 우 선적으로 반파 배전압회로를 적용한 UPS 인버터를 개발하 였다. 통상 $220 \mathrm{VAC}$ 입력 전압이 $300 \mathrm{VDC}$ 전압으로 변환되 며 $\mathrm{DC}$ 전압의 $1 / 2$ 정도의 전압 범위에서 교류신호를 발생 시키도록 설계한다.

본 장치가 동작 중 이상 현상이 발생할 때 주 제어부에

서는 이상 상태를 감지하고 외부 알람 등으로 이상 상태 경보를 출력 하지만 외부 부하의 심각한 결함이 발생 되거 나, 내부 부품에서 이상이 발생되었을 때 주제어부가 최종 적으로 판단, 전원 공급을 $\mathrm{BY}-\mathrm{PASS}$ 출력으로 절환시키고 내부 UPS 인버터에 공급되는 전기를 차단하여 발화 등 사 고를 방지하는 장치이다. 이상 발생 시 주제어부는 이를 감 지하고 최종적으로 전원 차단 상황으로 판단될 때, 부하 측 전원 공급을 $\mathrm{BY}-\mathrm{PASS}$ 로 전환 후 출력 단자로 신호를 출 력 시킨다.

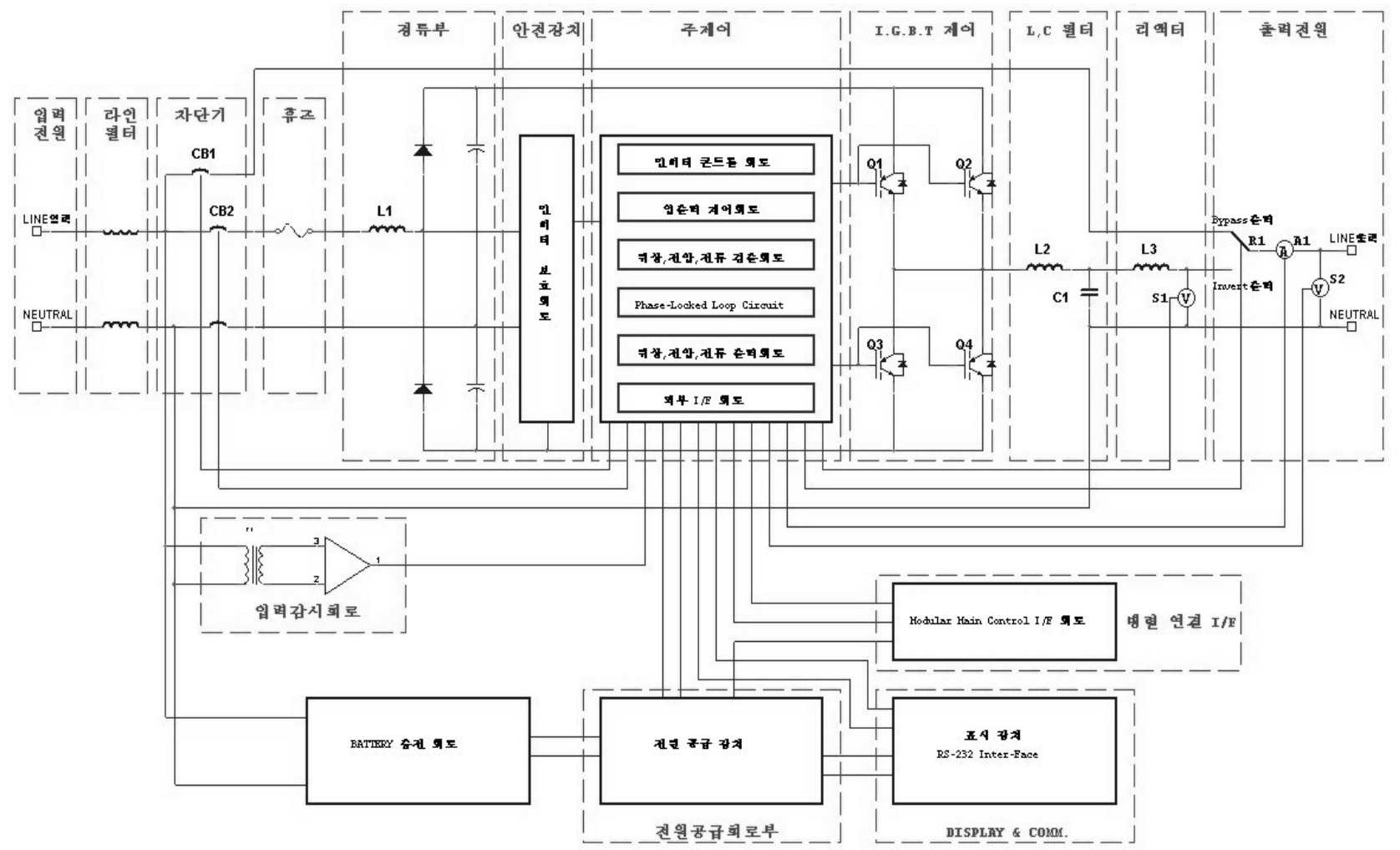

Fig. 2. Entire circuit configuration of the PRS 
입력된 신호는 Q1을 동작시켜 Fig. 2 휴즈부의 정격 휴 즈를 강제 단락시킨다. 이때 주 제어부는 CT1에 흐르는 전 류를 전류감지 단자로 검출하고 휴즈가 단선될 때까지 전 류를 증가시키면서 제어한다. 휴즈 단선 확인 후 외부 경보 를 통해 신속한 초치를 취할 수 있도록 한다. 이상 발생에 대한 죄종적인 규격 설정은 $\mathrm{KS} \mathrm{C} 4310$ 시험안전규격에 준 한다.

2) 세부 회로 구성 및 동작

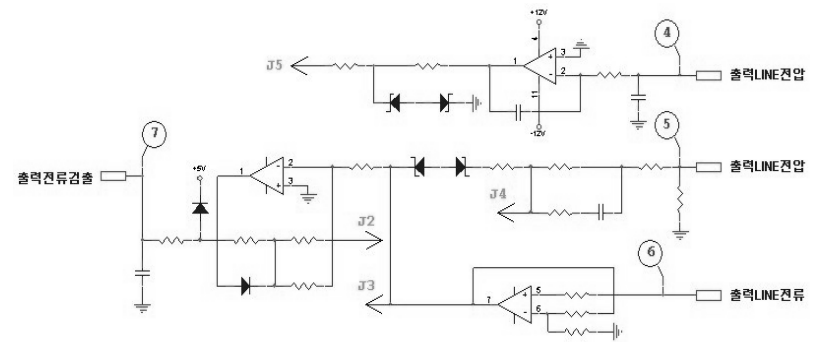

Fig. 3. The output current detection and output voltage of main control unit, and current FEEDBACK signal

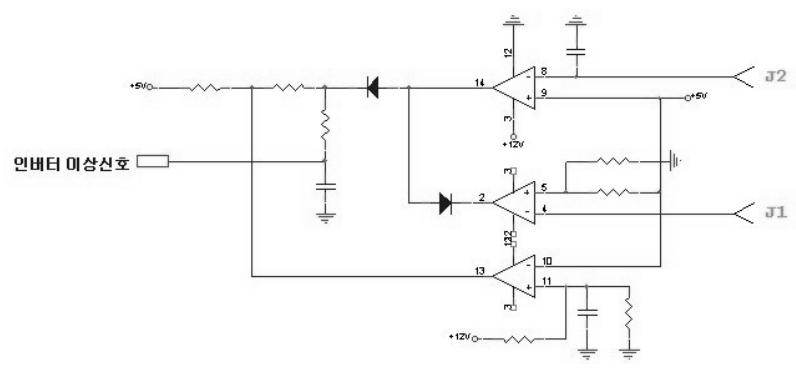

Fig. 4. Fault signal detection circuit of Inverter of the main control unit

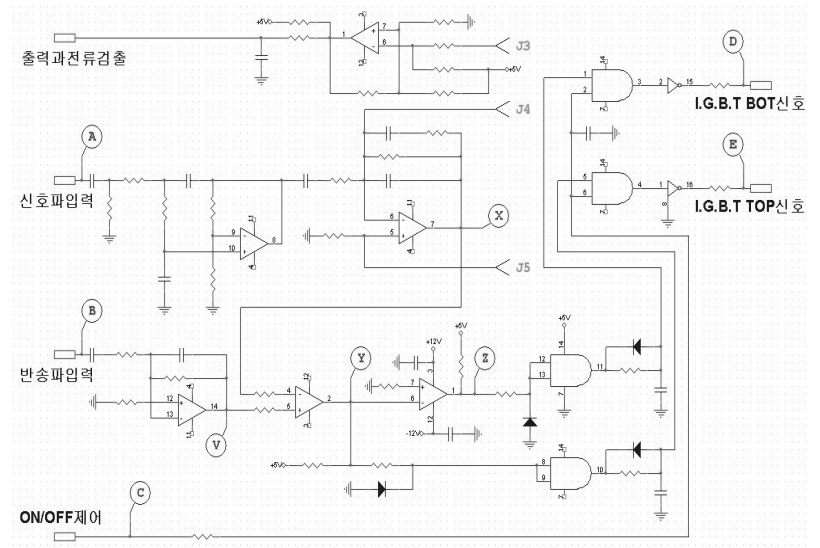

Fig. 5. The inverter output signal generating circuit and control circuit in Main Control Unit

Fig. 3을 통하여 주제어부 출력전류 감지와 출력전압, 전 류 FEED-BACK 신호를 알 수 있다. Fig. 3의 입출력 감지 회로는 별개로 구성되어 있고 입력되는 상용전압을 감지하
여 전압, 주파수, 위상데이터를 감지하고 입력 상태가 정상 일 때 Fig. 2 차단기부에 있는 $\mathrm{CB1}$ 을 동작시켜 부하 측으로 입력 전원을 공급한다. 부하 측에 전원을 정상 공급한 후 주제어부는 $\mathrm{CB} 2$ 를 $\mathrm{ON}$ 인버터 측에 전원을 공급한다.

Fig. 4는 주제어부 인버터 이상 신호 감지회로를 보여준다.

Fig. 5는 주제어부 인버터 출력신호 발생과 제어회로르르 보여준다. Fig. 5에서 보는 바와 같이, 주제어부는 입력신호 에서 검출한 신호를 기준으로 (B)점 반송파입력 단자에 반송 파신호를 발생시키고, (V)점은 입력된 $20 \mathrm{KHz}$ 구형파 신호를 삼각파 신호로 변환시키는 회로이다.

다음으로 (A)점 신호파 입력 단자에 PLL회로와 동기시킨 신호파 출력을 발생시킨다. 신호파 출력은 복잡한 과정으로 생성되고 이신호가 출력 파형의 형태를 결정하고 사인파 신 호에 대입된 부호 신호를 출력 UPS 인버터를 직접 제어하 는 기준 신호로 사용된다. 준비된 반송파입력, 신호파 입력 을 IGBT부로 전달 인버터 동작을 시작한다.

Fig. 2의 IGBT부, LC필터부, 리액터부를 통하여 발생된 교류신호는 $\mathrm{S} 1$ 센서를 통해 최종 확인하고 정상적인 출력 파형일 때 $\mathrm{R} 1$ 을 동작시켜 $\mathrm{ON}-\mathrm{LINE}$ 으로 출력 신호를 절환 부하 측으로 전원을 공급한다.

\section{4. 실험 측정결과 및 분석}

상기 과정에서 전체적인 회로 설계와 동작 흐름을 기술하 였으며, 회로 각 부분의 주요 동작 파형은 다음과 같다.

Fig. 6은 Fig. 3에서의 주제어부 출력전류 감지 및 출력전 압, 전류 $\mathrm{FEED}-\mathrm{BACK}$ 신호에서의 (7) 출력신호 파형을 나 타내며, 안정적인 파형이 유지됨을 알수 있다.

Fig. 7은 Fig. 5에서의 주제어부 인버터 이상 신호 감지회 로에서의 (B), (V) 단자의 출력신호 파형을 보여준다.

Fig. 8은 출력전류의 최종 검출을 위한 Fig. 3,5 의 J5, $\mathrm{J} 4, \mathrm{~J} 2$, (7)에서의 신호 파형을 나타낸다. 그리고, Fig. 9는 주 제어부 IGBT의 최종 출력 (D), (E) 포인트에서의 신호파형을 나타낸다. 그림의 파형에서 왼쪽에서 오른쪽 기호 순서대로, 파형의 위쪽 파형에서 아래 순서의 파형을 나타낸다. 이와 같은 신호파형들이 상용 전원과 인버터 신호와 유기적인 관 계로 상용전원의 이상 시에도 인버터가 정상적인 전력을 공 급함을 알 수 있다.

특히, Fig. 10은 단상 상용전원을 강제적인 순간정전 발생 시에도 파형 위상 변화 없이 인버터 출력 전압의 정상적인 파형을 보여준다. 그림에서 위의 실선은 인버터에서의 전원 을 나타내며, 점선은 상용전원을 나타낸다. 아래 그래프 그 림에서는 일정 시간 후 정전이 발생되었을 때의 상태를 보 여 주는데, 상용전원 입력이 순간 변동되어도 인버터 출력 은 일정하게 출력됨을 나타낸다. 


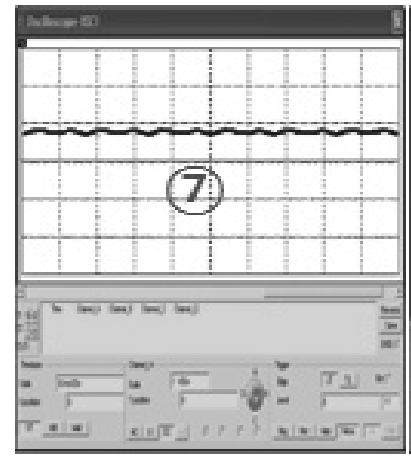

Fig. 6. The output signal waveform of (7) the output current detection of FEED-

BACK signal in Fig. 3

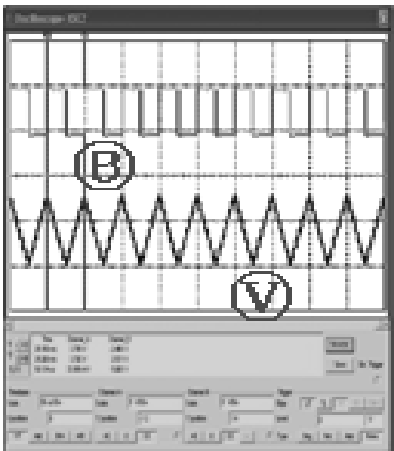

Fig. 7. The output signal waveforms of (B), (V) terminal over the abnormal signal in the circuit of the inverter of the main control unit

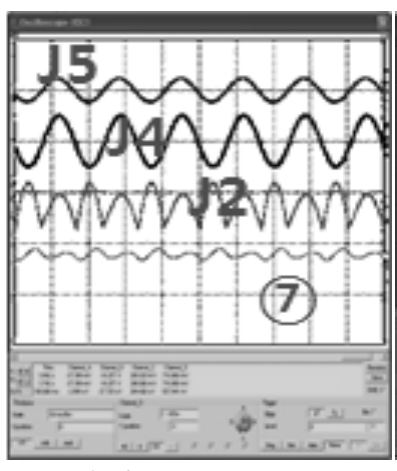

Fig. 8. Signal waveform on J5, J4, J2, (7) for the final detection of the output curren

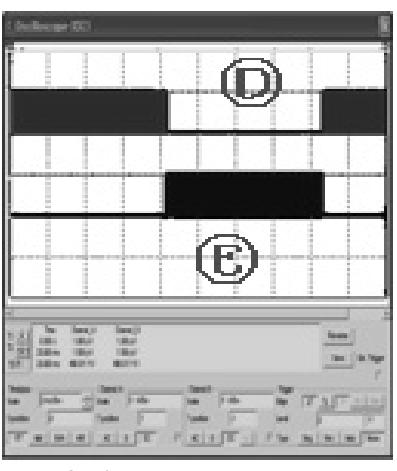

Fig. 9. Signal waveform of the final output IGBT (D), (E) point in Fig. 2
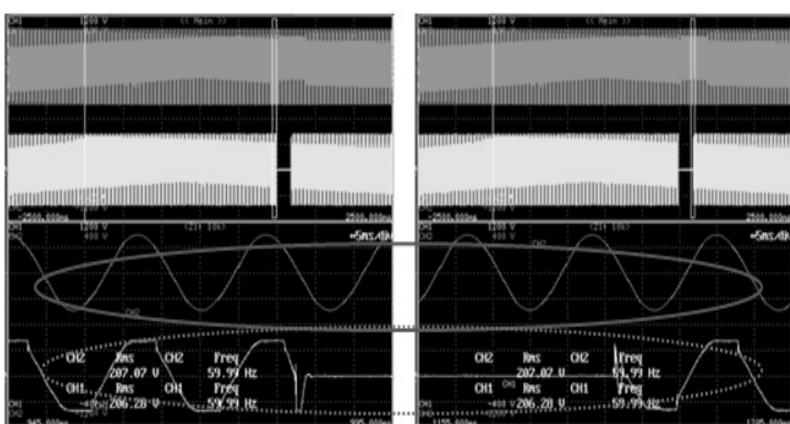

Fig. 10. Inverter power status in case of Single-phase commercial power outage

\section{5. 결 론}

본 논문을 통하여, 충/방전 전력검출용과 전력저장용 충/ 방전 회로를 본 눈문에서 제시된 바와 같이 개발하였다. 또 한 효율을 높이기 위하여 Transless Power Circuit DC-AC 인버터를 개발하였다. 특히 상용전원의 위상을 맞추기 위하 여, 전압 추적 회로를 사용하였다. 뿐만 아니라, 상용전원과 병렬연결하는 기술을 개발하였으며, 상용전원과 저장전력
공급 비율을 자동 조절 기술을 개발하였다. 단상은 $3 \mathrm{KW}$ 까 지 제공이 가능하도록 개발하였으며, 이를 통하여, 각 기능 별 개별 테스트와 통합테스트를 실시하여 올바른 작동여부 와 그 성능을 확인하였다. 본 논문에서는 지면상 그 전체를 표시하기에 어려움이 있지만, 그 일부를 제시하였다.

본 기술제품은 소형, 경량 및 고효율 제품 등으로 피크치 전원 제어 및 에너지 저장장치와의 병합연결 기술 구현에 큰 의미가 있다고 해도 과언이 아니다. 본 연구 실험을 통 하여, 대형 $\mathrm{ESS}$ 와 차별화가 기대되며, 민간이나 관공서용으 로 저렴한 가격으로 시장에 진입하기가 쉬우리라 전망된다. 또, 본 시험 결과를 토대로 병렬제어 기능으로 용량별 선택 과 접근이 용이하다.

본 연구는 상용전원과 병렬연결 제어하는 핵심기술로, 가 변임피던스 제어를 지속적으로 연구 개발하여 무정전 전원 장치의 저장전력을 상용전원과 연계함으로써, 기존의 무정 전 전원장치에서 구현을 못하고 있는 저장전력 사용시간을 획기적으로 늘릴 수 있는 기술이기도 하다.

본 개발 제품은 단상 $3 \mathrm{KW}$ 용량으로 개발되었지만, 향후 장치 간 10 대를 병렬 연결을 할 수 있어, 단상은 최대 $30 \mathrm{KW}$ 까지 가능하리라 본다.

본 논문에서 제시된, 개발하고자 하는 제품은 전력 병합 기능을 이용한 지능형 UPS 전력제어기기로 '저장기능 + 인 버터기능 + 전력 병합기능’을 포함한 장치로, 태양광 등 대 체에너지 인버터로 사용 가능하며, 기존의 무정전 UPS를 대체할 수 있는 'UPS 기능 + 전력병합 기능'의 신개념 피크 치 전력 제어 시스템이라 할 수 있다. 향후에 보다 체계적 인 모니터와 실시간 감시를 위하여, 원격제어 $\mathrm{HW}$ 및 $\mathrm{SW}$ 개발이 필요하다.

\section{References}

[1] Jangmoo Lee, Changmin Lee, and Gildong Kim, "Review about Peak Power reduction utilizing Energy Storage System at AC Electric Railway", Fall Conference journal, The Korean Society for Railway, 2009.

[2] Jeonghoon Kim, Seong Ook Hwang, and Hakjoo Lee, "Considering the load leveling function for residential ESS Study on Estimating the fair funding", Journal of The Korean Institute of Electrical Engineers, 2014.

[3] Hong Won Pyo, "Overview of ESS Utilization as Demand Response Resources for Emergency back-up Load", The Korean Institute of Illuminating and Electrical Installation Engineers, pp.139-141, Nov., 2013.

[4] Daniel W. Hart, Soonchan Hong, Hee Jong Jeon, and Yongsoo Yun, Power Electron Engineerg, McGraw-Hill Korea, 2011.

[5] Foster, I., Kesselman, C., Nick, J., Tuecke, S., The Physiology of the Grid: an Open Grid Services Architecture for Distributed Systems Integration, Technical report, Global Grid Forum, 2002. 
[6] Single-phase double conversion UPS with ESS function: http://cafe.naver.com/sigongdo/89713, 2013.

[7] Jaesoo Yang and Donghan Kim, "Development of Power Merging System for Power Peak Load Curtailment", ISAAC 2013, IIBC, IPACT, pp.189-193, 2013.

[8] Share of energy production in 2010, the National Energy Information System Integration, 2010.

[9] Statistical compilations electricity trading, Korea Power Exchange, Dec., 2009.

[10] www.epsis.co.kr, EPSIS, Korea Power Exchange, 2011.

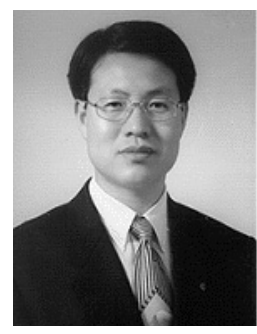

\section{양 재 수}

e-mail : jsyang@dankook.ac.kr

1981년 한국항공대학교 통신공학과

1985년 건국대학교 전자공학과(석사)

1993년 미 NJIT 전기 및 컴퓨터(공학박사)

1981년 MIC 통신사무관

1982년 2006년 KT 기술부장, 전화국장, 인터넷사업국장, 수도권 강북본부 사업지원총괄담당상무

2006년 2011년 광운대학교 교수

2007년 2011년 경기도 정보화특별보좌관

2011년 현 재 단국대학교 교수

관심분야: ICT융합기술, 정보보안, RFID/IP-USN, 정보통신

산업정책, 그린 에너지, $\mathrm{u}-\mathrm{City}$

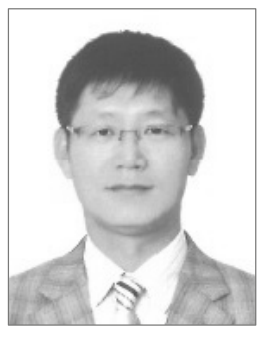

김 동 한

e-mail :hk29682@naver.com

1984년 경희대학교 전자공학과(학사)

1985년 1987년 대한항공(N.Y.지점 근무)

2014년 현 재 경기정보산업협회 사업이사 /그린에너지융합위원장

관심분야:퍼지 시스템, 전문가시스템,

신경망, 교통제어

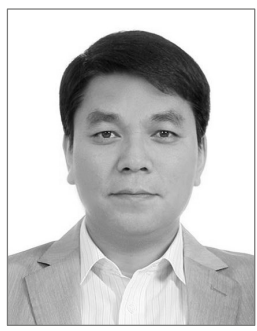

\section{김 만 도}

e-mail :mdkim104@naver.com

1992년 경일대학교 전자공학과(학사)

2000년 광운대학교 컴퓨터공학(석사)

1995년 2001년 POSCON(현POSCO ICT)

연구소 $\mathrm{DCS}$ 개발

2001년 2008년 팬택연구소 WCDMA 개발

2011년 현 재 이플러스 연구소장

2012년 현 재 수원과학대학교 전자과 겸임교수

관심분야: ICT융합기술, 공장자동화, $\mathrm{USN}$, 그린 에너지 